\title{
Congenital Unilateral Hypoplasia of the Orbicularis Oris Muscle: A Rare Cause of Congenital Unilateral Upper Lip Palsy
}

\author{
Sadık Şentürk ${ }^{1}$, Duran Efe ${ }^{2}$ \\ ${ }^{1}$ Department of Plastic and Reconstructive Surgery, Mevlana (Rumi) University Hospital, Konya, Turkey; ${ }^{2}$ Department of Radiology, \\ Mevlana (Rumi) University Hospital, Konya, Turkey. \\ Email: ssenturk@mevlana.edu.tr, duranefe@hotmail.com
}

Received January $14^{\text {th }}, 2013$; revised February $20^{\text {th }}, 2013$; accepted February $28^{\text {th }}, 2013$

Copyright (C) 2013 Sadık Şentürk, Duran Efe. This is an open access article distributed under the Creative Commons Attribution License, which permits unrestricted use, distribution, and reproduction in any medium, provided the original work is properly cited.

\begin{abstract}
Asymmetric facial appearance may originate from abnormalities of facial musculature or facial innervation. Congenital absence or hypoplasia of facial muscles has not been known except for the depressor anguli oris muscle. Even, congenital unilateral hypoplasia of the orbicularis oris muscle cause of unilateral upper lip palsy has not been reported in the literature up to day. In this report, we present a patient with congenital unilateral upper lip palsy although the facial nerve was normal.
\end{abstract}

Keywords: Congenital Upper Lip Palsy; Unilateral Hypoplasia; Orbicularis Oris Muscle

\section{Introduction}

Asymmetric facial appearance may occur abnormalities of facial musculature or facial innervation. Asymmetric face is occur in $0.2 \%-0.6 \%$ of newborns [1-3]. Congenital absence or hypoplasia of facial muscles is uncommon anomaly causing a remarkable aesthetic deformity. Congenital absence or hypoplasia of facial muscles has not been known except for the depressor anguli oris muscle. Even, congenital unilateral hypoplasia of the orbicularis oris muscle cause of unilateral upper lip palsy has not been reported in the literature up to day. In this report, we present a patient with congenital unilateral upper lip palsy although the facial nerve was normal. Clinical presentation of patients with asymmetric face is characterized by the lip appears distorted towards the healthy side. Diagnosis can be detectable by the clinical picture, an electromyographic and magnetic resonance imaging study $[4,5]$.

\section{Case Report}

A 33-year-old girl presented with asymmetric movement of upper lip when she whistled and ate. The patient denied having any previous trauma, major infection, or facial surgery and was unaware of any other associated congenital deformity. Her medical history was otherwise unremarkable. The patient was born at term after an uneventful pregnancy. Physical examination revealed thin unilateral upper lip. The face appeared symmetric at rest (Figure 1). The patient had inward deviation of right upper lip when she whistled (Figure 2). Facial nerve function, as determined by frowning/forehead, wrinkling, eye closure, nasolabial fold depth, and tearing, was symmetric. Neurologic exam was normal. Magnetic resonance imaging of the upper lip were unilateral hypoplasia of the orbicularis oris muscle (Figure 3).

\section{Discussion}

Asymmetric facial appearance may occur abnormalities of facial musculature or facial innervation. Asymmetric face is occur in $0.2 \%-0.6 \%$ of newborns [1-3]. Congenital absence or hypoplasia of facial muscles is uncommon anomaly causing a remarkable aesthetic deformity. Congenital absence or hypoplasia of facial muscles has not been known except for the depressor anguli oris muscle. Even, congenital unilateral hypoplasia of the orbicularis oris muscle has not been reported in the literature up to day. Clinical presentation of patients with congenital unilateral hypoplasia of the orbicularis oris includes typical clinical picture, which includes upper lip asymmetry during whistling while forehead wrinkling, 


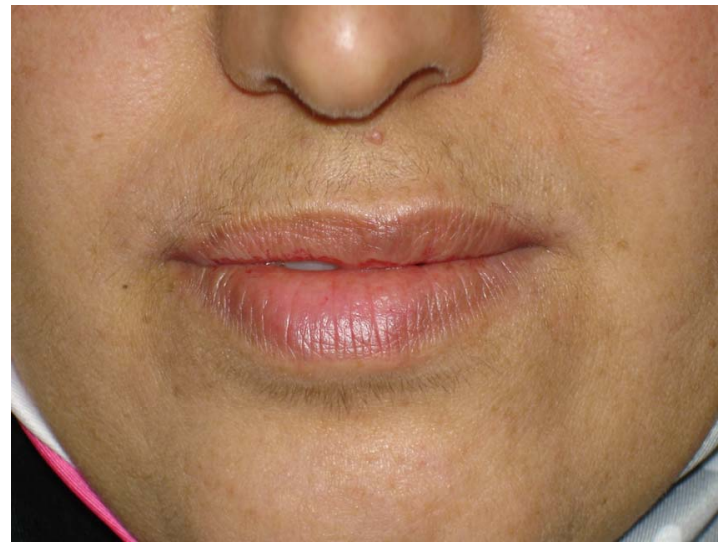

Figure 1. Patient with right-sided asymmetric upper lip at rest.

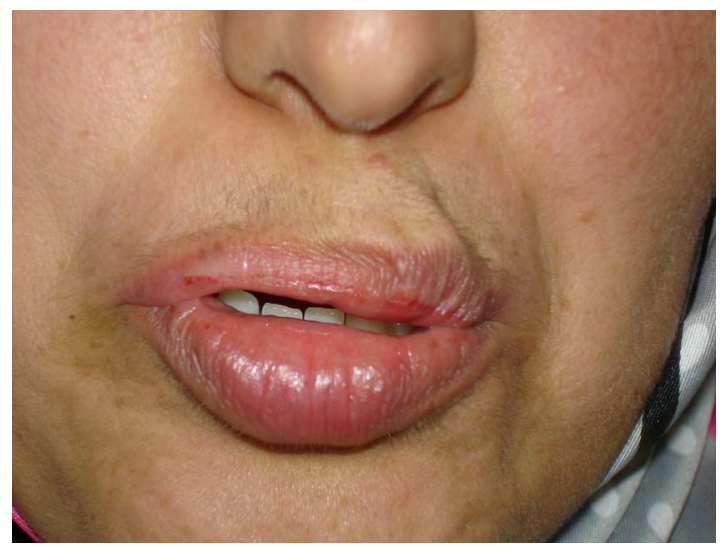

Figure 2. The upper lip is pulled toward the intact left side.

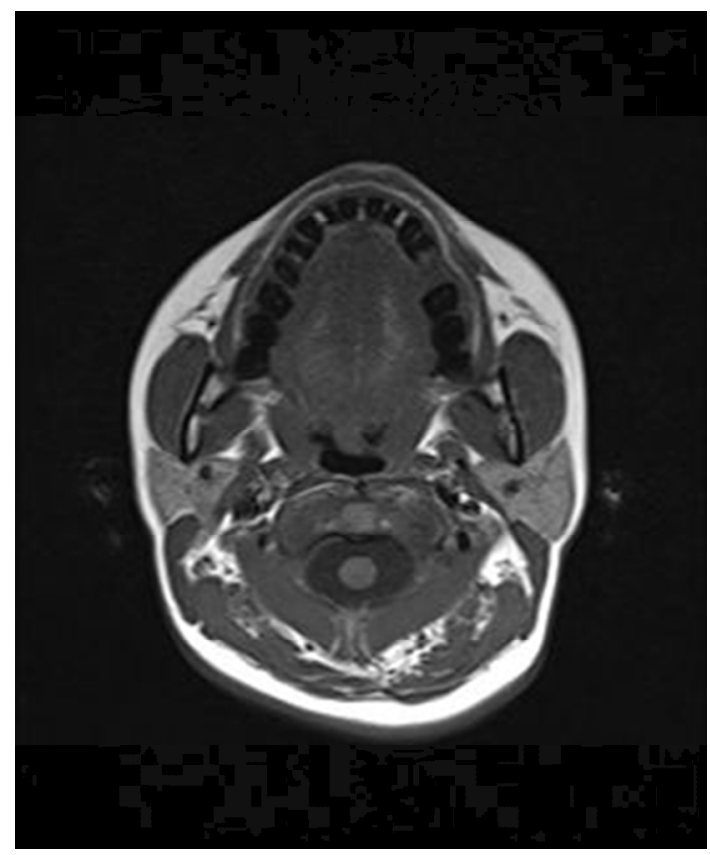

Figure 3. Magnetic resonance imaging of the upper lip were unilateral hypoplasia of the orbicularis oris muscle. nasolabial fold depth, and eye closure remain intact and equal on both side. Diagnosis can be detectable by the clinical picture, an electromyographic and magnetic resonance imaging study [4,5]. Differential diagnosis of upper lip asymmetry includes facial nerve paralysis and trauma factors. Facial nerve lesions may cause weakness of facial expressions; however, congenital unilateral hypoplasia of the orbicularis oris afflicts upper lip while other functions of facial nerves are preserved.

Congenital palsy of the depressor anguli oris muscle, said to have an asymmetric crying facies is characterized by facial asymmetry that is usually first noticed when the infant cries, because half of the lower lip manifests a pulled-down, outward appearance. It is also known as congenital unilateral lower lip palsy, congenital hypoplasia of the depressor anguli oris muscle, and partial facial paralysis [6-8]. A wide variety of anomalies involving cardiovascular, gastrointestinal, genitourinary, skeletal, and central nervous systems may be seen in children with congenital hypoplasia of depressor anguli oris [9-13].

The pathogenesis of congenital absence or hypoplasia of facial muscles has not been established. Up to day, intrauterine molding, viral infection during pregnancy, and heredity have been suggested as causative factor $[14,15]$. Nonetheless, pathogenesis of congenital absence or hypoplasia of facial muscles appears to be multifactorrial and further studies are needed to elucidate it.

As a result, the present case highlights the clinical presentation of congenital unilateral hypoplasia of the orbicularis oris muscle that causes asymmetric face.

\section{REFERENCES}

[1] S. O. Ulualp and R. Deskin, "Congenital Unilateral Hypoplasia of Depressor Anguli Oris," Case Reports in Pediatrics, Vol. 2012, 2012, Article ID: 507248.

[2] A. H. Parmelee, "Molding Due to Intra-Uterine Posture," American Journal of Diseases of Children, Vol. 42, No. 5, 1931, pp. 1155-1159.

[3] S. E. Levin, N. H. Silverman and S. Milner, "Hypoplasia or Absence of the Depressor Anguli Oris Muscle and Congenital Abnormalities, with Special Reference to the Cardiofacial Syndrome," South African Medical Journal, Vol. 61, No. 7, 1982, pp. 227-231.

[4] W. Walter, "Congenital Hypoplasia of the Depressor Anguli Oris Muscle," Archives of Pediatrics \& Adolescent Medicine, Vol. 150, 1996, p. 326.

[5] R. Olszewski, Y. Liu, T. Duprez, T. M. Xu and H. Reychler, "Three-Dimensional Appearance of the Lips Muscles with Three-Dimensional Isotropic MRI: In Vivo Study," International Journal of Computer Assisted Radiology, Vol. 4, No. 4, 2009, pp. 349-352. doi:10.1007/s11548-009-0352-8

[6] U. Akikazu, A. Kouzou, S. Sara, S. Hiroyuki, M. Hu- 
miaki, Y. Shinya and I. Masaharu, "A Simple Reconstruction for Congenital unilateral Lower Lip Palsy," Plastic \& Reconstructive Surgery, Vol. 120, No. 1, 2007, pp. 238-244. doi:10.1097/01.prs.0000264062.64251.10

[7] K. E. Pape and D. Pickering, "Asymmetric Crying Facies: An Index of Other Congenital Anomalies," Journal of Pediatrics, Vol. 81, No. 1, 1972, pp. 21-30. doi:10.1016/S0022-3476(72)80368-8

[8] T. Kobayashi, "Congenital Unilateral Lower Lip Palsy," Acta Otolaryngologica, Vol. 88, No. 1-6, 1979, pp. 303309. doi:10.3109/00016487909137173

[9] G. G. Caylar, “An 'Epidemic' of Congenital Facial Paresis and Heart Disease," Pediatrics, Vol. 40, No. 4, 1967, pp. 666-668.

[10] M. Perlman and S. H. Reisner, "Asymmetric Crying Facies and Congenital Anomalies," Archives of Disease in Childhood, Vol. 48, No. 8, 1973, pp. 627-629. doi:10.1136/adc.48.8.627

[11] D. Alexiou, C. Manolidis and G. Papaevangellou, "Frequency of Other Malformations in Congenital Hypoplasia of Depressor Anguli Oris Muscle Syndrome," Archives of Disease in Childhood, Vol. 51, No. 11, 1976, pp. 891893. doi:10.1136/adc.51.11.891

[12] D. Rioja-Mazza, E. Lieber, V. Kamath and R. Kalpatthi, "Asymmetric Crying Facies: A Possible Marker for Congenital Malformations," Journal of Maternal-Fetal and Neonatal Medicine, Vol. 18, No. 4, 2005, pp. 275-277. doi:10.1080/14767050500246482

[13] C. Papadatos, D. Alexiou and D. Nicolopoulos, "Congenital Hypoplasia of Depressor Anguli Oris Muscle. A Genetically Determined Condition?" Archives of Disease in Childhood, Vol. 49, No. 12, 1974, pp. 927-931. doi:10.1136/adc.49.12.927

[14] M. Akcakus, Y. Ozkul, T. Gunes, et al., "Associated Anomalies in Asymmetric Crying Facies and 22q11 Deletion," Genetic Counseling, Vol. 14, No. 3, 2003, pp. 325-330.

[15] W. R. Hapner, "Some Observations on Facial Paresis in the Newborn Infant: Etiology and Incidence," Pediatrics, Vol. 8, No. 4, 1951, pp. 494-497. 